\title{
New modeling of reconfigurable microstrip antenna using hybrid structure of simulation driven and knowledge based artificial neural networks
}

\author{
Simülasyona ve bilgi tabanlı yapay sinir ağlarına dayalı hibrid yapı \\ kullanarak yeniden yapılandırılabilir mikroşerit anteni yeni modelenmesi
}

\author{
Ashrf AOAD ${ }^{1 *}$ (ID) Zafer AYDIN ${ }^{2}$ \\ ${ }^{1}$ Deparment of Electrical-Electronics Engineering, Faculty of Engineering and Natural Sciences, Istanbul Sabahattin Zaim University, \\ Istanbul, Turkey. \\ esref.osmanlioglu@izu.edu.tr \\ 2Deparment of Computer Engineering, Engineering Faculty, Abdullah Gul University, Kayseri, Turkey. \\ zafer.aydin@agu.edu.tr
}

\section{Abstract}

Knowledge-based modeling has a critical role to embed existing knowledge to improve modeling performance. Since reconfigurable antenna can provide more operational frequencies than the classical antennas, a knowledge-based hybrid structure is used in this work to obtain efficient model and producing optimum new models for a reconfigurable microstrip antenna. The hybrid structure consists of two phases. The first phase generates initial knowledge which is used in knowledge-based modeling structure to obtain design parameters. Artificial neural network based multilayer perceptron can generate necessary knowledge for a knowledge-based model after the training process. Knowledge-based modeling improves the accuracy of the initial model to determine design parameters corresponding to the design target. Source difference, prior knowledge Input and prior knowledge input with difference can be applied to realize an efficient knowledgebased strategy. 3D-EM simulation generates the new model in terms of the design parameters of the proposed application. It has three switching states for operating, which are organized by two resistor circuits representing ON/OFF states. Switch positions and geometrical parameters can be used for satisfying design targets between $1 \mathrm{GHz}$ and $6 \mathrm{GHz}$ for the efficient antenna design.

Keywords: Artificial neural networks, Knowledge-based models, Reconfigurable microstrip antenna, Resistor circuits.

\section{Introduction}

The recent development of reconfigurable microstrip antennas is rapidly growing especially in telecommunication technologies [1]. They are gained considerable attention in the IEEE $802.11 \mathrm{n}$ standard, MIMO radar systems, portable computers and 5G cellular technologies such as WiMAX and long-term evolution (LTE) [2],[3]. Through changing the shape of the structure of the antenna by connecting/disconnecting some radiating parts, types of dielectric materials and feeding systems, different characteristics can be realized such as frequency bands, radiation patterns, directivity, etc. In addition, they have excellent properties as light weights, easily fabricated, small electrical dimensions (length, breadth and height.), low price and profile compared to conventional antennas [2]. Various switching mechanisms have been applied for designing reconfigurable antennas. Set of those (e.g. thin

\section{Öz}

Bilgi tabanlı modelleme, modelleme performansını geliştirmek için mevcut bilgiyi içine katmak için kritik bir role sahiptir. Yeniden yapılandirlabilir anten, klasik antenlerden daha fazla operasyonel frekans sağlayabildiğinden, bu çalıșmada bilgi tabanlı bir hibrid yapı, verimli bir model elde etmek ve ayn zamanda yeniden yapılandırılabilir bir N-şekilli mikroşerit anten (RNSMA) için optimum yeni çözümler üretmek için kullanılmıștır. Hibrid yapı iki așamadan olușmaktadır. İlk aşama, tasarım parametrelerini elde etmek için bilgi tabanlı modelleme yapısında kullanılan bașlangıç bilgisini üretmektedir. Yapay sinir ağı tabanlı çok katmanlı algılayıcı, eğitim sürecinden sonra bilgi tabanlı bir model için gerekli bilgiyi üretebilir. Bilgi tabanl modelleme, tasarım hedefine karșlllk gelen tasarım parametrelerini belirlemek için başlangıç modelinin doğruluğunu geliştirir. Verimli bilgi temelli bir stratejiyi gerçeklestirmek için Ön Bilgi Giriși (PKI), Kaynak Farkı (SD) ve Ön Bilgi Giriși ile Fark (PKID) uygulanabilir. 3B-EM simülasyonu, RNSMA'nın tasarım parametrelerine bağlı olarak yeni çözümü üretir. Önerilen anten, ACIK/KAPALI durumlarını kullanarak iki direnç devresi tarafindan kontrol edilen üç çalışma moduna sahiptir. Anahtar konumları ve geometrik parametreler verimli bir anten tasarımı için 1 $\mathrm{GHz}$ ve $6 \mathrm{GHz}$ arasinda tasarım hedeflerini karşılamak için kullanılabilir.

Anahtar kelimeler: Yapay sinir ağı, Bilgi tabanlı modelleme, Yeniden yapılandırılabilir anten, Direnç devresi.

${ }^{*}$ Corresponding author/Yazışılan Yazar

film microstrip, MEMS, resistors, PIN diodes, varactors and smart material) have played a major role for achieving different results as resonant frequencies, wideband and polarization diversity [1],[4]. In this study, three switching states have been researched with two resistor circuits which are $\mathrm{ON}-\mathrm{ON}, \mathrm{ON}-\mathrm{OFF}$ and OFF-OFF. These states have a wide area of operating frequencies that make the proposed antenna more advisable when compared to other reconfigurable antennas controlled by different switching mechanisms studied in [5]-[8]. Therefore, the idea of using resistor circuits is for switching states that can minimize the complexity and non-linearity of the proposed antenna compared to today's wireless communication systems [4]. It is possible to model and optimize different types of antennas using different optimization methods, one of the most important is ANN methods [9],[10]. They provide a general structure for modelling non-linear links between various outputs and inputs related to the problem (control, remote 
sensing, pattern recognition, medical, telecommunications, speech processing, and more applications). They are also much faster than 3D-EM simulation for achieving results. Therefore, ANNs are considered as an optimization and modeling process for the antenna design, microwave device, electronic circuits and signal integrity analysis [9]-[11]. They are computational algorithms. It intended to simulate the action of different systems by data. In certain cases, data should be available from designed/modeled applications represented sometimes by data collected from equivalent, covariance, undeformed and deformed models, in addition to semi-analytical, math and empirical equations [10]. In knowledge-based/added ANN models, the present knowledge (data/any information) is integrated as input sometimes as target vectors to learn in the fine model [11],[12]. They have more accuracy, often faster, have better interpolation and extrapolation data process and require minimal training knowledge compared to traditional ANN (e.g. Multilayer perceptron (MLP)) [9],[13].

This paper supports the growing needs in the application of ANNs in reconfigurable antenna design areas. ANNs depend on enough training data for modelling and optimizing the results of any microwave application, in which their accuracy also depends on the data presented during the training process step. In this application, training data is generated by CST-EM simulation software that is based on the Finite Integration Technique (FIT).

In this study, novel models (solutions) are presented by using the hybrid structure for modeling the reconfigurable $\mathrm{N}$-shaped microstrip antenna as an alternative technique to only use 3D-EM simulations [14]. The structure is developed to contain two phases, the first phase contains two processing steps: MLP as a first training step followed by means of knowledge-added methods as a second training step. Knowledge-added methods are: (1) prior knowledge input (PKI), (2) source difference (SD) and (3) prior knowledge input with difference (PKID) methods $[9],[10],[14]$. However, in the hybrid structure, the frequency samples are provided as an input and the geometrical characteristics of the model/proposed antenna as an output, and consequently the learning process is inversely achieved. Thus, the hybrid structure was reversed to start processing from right to left direction as explained in paragraph 3 . It is significant to note that the output of MLP presents a coarse model/information in some cases, which is subsequently trained by the knowledge-added methods. In the last, the characteristic parameters have been taken out from the ANNs are designed by the 3D-EM CST software as a second phase to find new models as goaled hence new operational frequencies which can be contributed in different wireless communication applications that have operating frequency range between 1-6 GHz such as L-band, S-band, and C-band. The proposed models confirm to be especially useful in case of the frequency samples are only the input used to produce several new models with several geometrical dimensions. Improved accuracy is outlined by the normalized mean absolute error (NMARE) between the predicted output and the target of the model for the return loss (RL).

\section{Reconfigurable antenna design}

The antenna being studied introduces a new reconfigurable microstrip antenna (RNSMA) that the radiation conductor is configured in the shape of capital " $\mathrm{N}$ " letter. This RNSMA is made up of three different material sheets and a feeding system (Coaxial cable). The radiation conductor (first sheet) consists of two faced triangles separated by mid rectangular strip as shown in Figure 1(a). The length of parameters of $L_{1}, L_{2}, L_{3}, W_{1}$ and $W_{4}$ set to $0.8 \mathrm{~cm}$ while the width of mid rectangular strip set to $0.4 \mathrm{~cm}$. They are typed on a dielectric substrate of FR-4 (mid sheet) with a thickness set to $0.2 \mathrm{~cm}$ and a relative permittivity of 4.3. The ground plane (last sheet) is typed on the back side of the dielectric. $W_{2}$ and $W_{3}$ are introduced as empty spaces between the two triangles and the mid conductor set to $0.2 \mathrm{~cm}$ that contains two resistor circuits $\left(R C_{1}\right.$ and $\left.R C_{2}\right)$. Each circuit contains two different resistors of value and in parallel mode, the main rule of $R C_{1}$ and $R C_{2}$ is to control the flow of the electrical current hence they might permit appearing new results. Ordinarily, resistors work by scattering power as heat and minimizing the flow of electricity through it. They are passive electrical components that act as variable material at radio frequency (RF) and microwave wireless systems. They are placed in the position of the upper left (between $A \& B=0.2 \mathrm{~cm}$ ) and lower right (between C \& D = 0.2 $\mathrm{cm}$ ) parts of the triangle conductors to do a perfect shared current paths on the conductors basing on their switching states $\left(S W_{1} \& S W_{2}\right)$ as shown in Figure 2(a). As it is known, a switch has two functions, a short circuit when closed and an open circuit when open. Therefore, when switches $\left(S W_{1} \& S W_{2}\right)$ in the circuits are switched off (OFF-OFF state/between $t_{2}-t_{3}$ ), the current is only distributed on the mid conductor that is minimizing the non-linearity. In the case of both switches in the circuits are switched on (ON-ON state/between $t_{0}-t_{1}$ ), the effective length of the RNSMA begins to be higher which maximizes the non-linearity. If one of the switches in the circuits is switched off while the other is switched on (ON-OFF state/between $t_{1}-t_{2}$ ), the effective conductors are the mid rectangle and the triangle that is linked to it causing mid non-linearity (see Figure 2(a \& b)).

The resistive value of the used resistors is limited by the forward biased DC current only. The resistor of $R_{O F F}$ has a large resistive value of $130 \mathrm{Ohms}$ to not permit distributing the DC current to the surface of the connected conductors, the resistor of $R_{O N}$ has a small resistive value of $5 \mathrm{Ohms}$ when used in the ON state as shown in Figure 2(b). Therefore, the current flowing through each resistor will be different as specified by Ohm's Law. The feeding system is located at the center $(0,0)$ of the middle conductor with an inside radius of $\left(65 \times 10^{-3} \mathrm{~cm}\right)$ as shown in Figure 1(b). Suppose the change in the resistive value of the shape of conductors and the resistors are $R$, the feeding source is $V(\mathrm{~V}$ is the voltage) and they are independently verified based on switching states, thus $I$ is a function of the two variables $I(V, R)$.

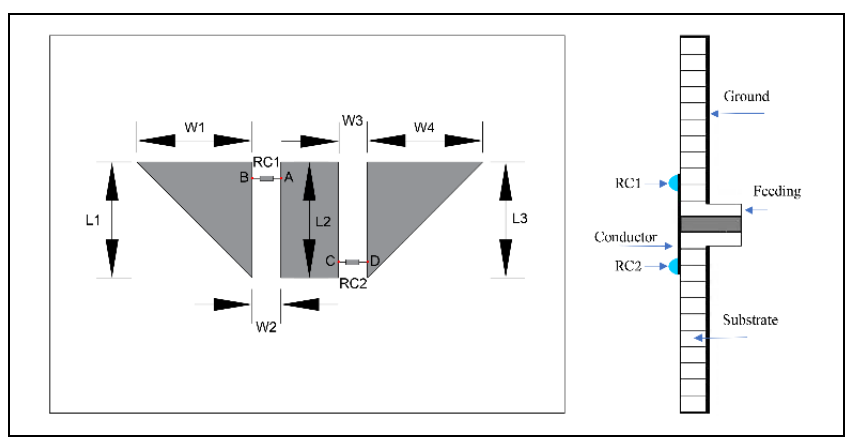

(a)

(b)

Figure 1. (a): Reconfigurable N-shaped microstrip antenna and (b): Side views. 


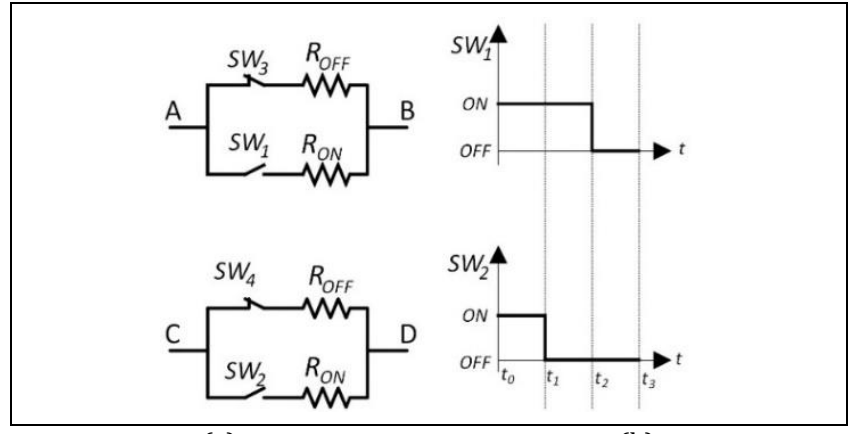

(a)

(b)

Figure 2. (a): Perspective of resistor circuits and (b): Switching states.

According to ohm's low, the resistive value of each resistor determines the amount of current flowing within that resistor as shown in Figure 2(a). The equation of parallel resistors specifies $\quad R C_{1}$ and $R C_{2}$ as $\left(R_{O F F} * R_{O N}\right) /\left(R_{O F F}+R_{O N}\right)$. Therefore, the resistive value of $R C_{1}$ or $R C_{2}$ is approximately close to the value of $R_{O N}$ in a situation in which $S W_{3}$ and $S W_{4}$ switched OFF or ON. In other word, switching state (ON or OFF) of $S W_{3}$ and/or $S W_{4}$ is not important because it is followed by high-value resistance $\left(R_{O F F}\right)$.

To accomplish this nonlinear function, the boundary of the generated training data (minimum and maximum values) for the antenna parameters are ranged as shown in Table 1.

Table 1. The range of generated training data.

\begin{tabular}{cccc}
\hline Parameters & Minimum & Maximum & Samples \\
\hline$L_{1}(\mathrm{~cm})$ & 0.8 & 2 & 5 \\
$L_{2}(\mathrm{~cm})$ & 0.7 & 2 & 5 \\
$L_{3}(\mathrm{~cm})$ & 0.65 & 2 & 5 \\
$W_{1}(\mathrm{~cm})$ & 0.5 & 1.2 & 5 \\
$W_{4}(\mathrm{~cm})$ & 0.5 & 1.2 & 5 \\
$R_{O N}(\Omega)$ & 5 & - & 1 \\
$R_{O F F}(\Omega)$ & - & 130 & 1 \\
$f_{i}(\mathrm{GHz})$ & 1 & 10 & 100 \\
\hline
\end{tabular}

\section{Proposed hybrid structure}

The hybrid structure has been developed presently that uses neural networks and 3D-EM simulation as its basis. The proposed hybrid structure consists of two phases which is the first phase has two data training/processing steps in the neural network area, then followed by 3D-EM simulator to design the output of the first and second step of the first phase for obtaining the novel models $\left(Y_{M L P}\right.$ and $\left.Y_{K B N N}\right)$ of the RNSMA as shown in Figure 3.

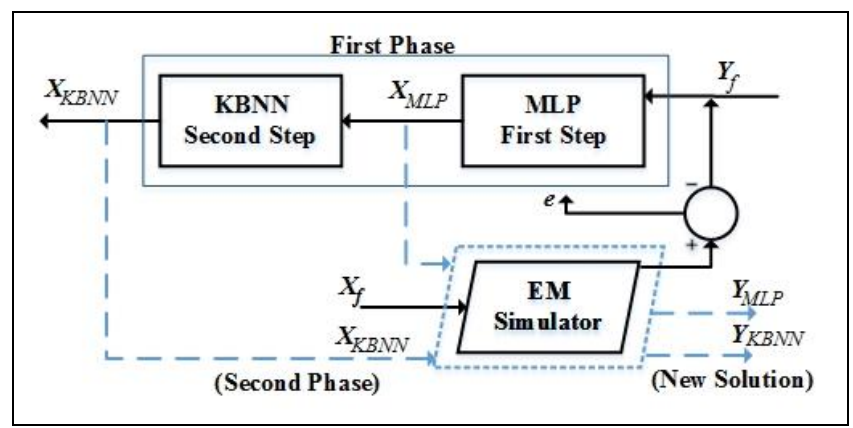

Figure 3. Two-phase data processing of the hybrid structure and producing new models.
The input for ANNs of the hybrid structure is only frequency samples $\left(Y_{f}=f_{f}\right)$, while the outputs are the required geometrical dimensions of the reconfigurable antenna model. ( $\mathrm{X}_{\mathrm{MLP}}$ is the result from 1 . st step and $\mathrm{X}_{\mathrm{KBNN}}$ is the result

from 2.nd step) as shown in Figure 3 and Figure 4. Furthermore, the output of the first training step is the input of the second training step in addition to extra knowledge as in case of PKI and PKID while the extra knowledge will be added to the target in SD method. The 3D-EM simulator is given as a mutual simulation part for generating training data beforehand the first phase and designing the result $\left(X_{M L P}\right.$ and $\left.X_{K B N N}\right)$ of the first phase to get novel models $\left(Y_{M L P} \& Y_{K B N N}\right)$ through the second training phase of the structure. The result obtained from MLP that is known as the first training step will go through the knowledge-based neural network (KBNN) that is known as the second training step which is shown as $X_{S D}, X_{P K I}$ and $X_{P K I D}$. During data processing of ANNs, applying the required training steps for adjusting synaptic weights and thresholds of their neurons. Therefore, the weight coefficient $(\omega)$ in the error function $(e)$ can be defined by

$$
\omega=\arg \underset{\omega}{\min }|| e_{n} \|, n=1,2,3, \ldots, N
$$

Where $n$ and $N$ represent the iteration number and the training data number for ANN modeling, respectively. The error measurement function is defined as:

$$
e_{n}=Y_{A N N s}^{n}-Y_{f}^{n}, \quad n=1,2,3, \ldots, N
$$

Where $Y_{f}^{n}$ represents the input and $Y_{A N N S}^{n}$ represents ANN models which is known here as $X_{M L P}$ and $X_{K B N N}$. Finally, after finishing the training process in the hybrid structure, the function can be defined as:

$$
X_{A N N S}=f_{A N N S}\left(Y_{f}\right)
$$

(1), (2) and (3) equations are considered as a general concept to the following ANN methods.

The training data generated by 3D-EM-simulator was 312,500samples which are computed by (4) of the five trained parameters of $L_{i}$ and $W_{j}$ for the proposed application as shown in Table 1.

$$
N_{t r}=Y_{f} \prod_{i=1}^{3}\left|L_{i}\right| \prod_{j=1}^{2}\left|W_{j}\right|
$$

Where $N_{t r}$ is the training sample numbers, $Y_{f}$ is frequency sample numbers (which is equal to 100), $\left|L_{i}\right|$ and $\left|W_{j}\right|$ are the number of samples generated for proposed antenna parameters $L_{i}$ and $W_{j}$ (which is equal to 5). Therefore, $N_{t r=}$ $100 \times 5^{5}=312,500$-samples. This large amount of training data has been minimized to be 3,125-samples. The obtained number of samples cover the data requirements. The minimization procedure depends on the artificial selection of optimum frequency samples available between $1-10 \mathrm{GHz}$ of the frequency band which has the lesser values of return losses. The frequency samples are 100 which are considered the input of the presented models and the output is 5 parameters which are the geometrical parameters of the proposed RNSMA. Therefore, the connection between the inputs of $Y$ vector and the outputs of $X$ vector are multi-dimensional and non-linear related to the problem (RNSMA). In the testing development 
stage, three testing data sets are selected in $\mathrm{ON}-\mathrm{ON}$ state. The first two testing data sets selected inside training data while the third is selected outside the training data which are applied to examine the accuracy, generalization capability and final model for interpolation and extrapolation data sets in addition to verify the actual predictive impact of the neural structure. In ON-OFF and OFF-OFF states, different methods of selection testing data have been made.

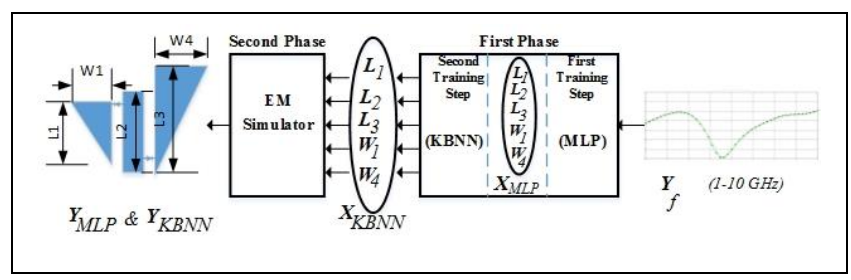

Figure 4. Perspective of produced new models by hybrid structure.

\subsection{Multilayer perceptron modeling method (MLP)}

MLP is an important and simplest modeling method. It is a class of feedforward neural networks, which is the processing method at the first step of the first phase as shown in the hybrid structure of Figure 3. In MLP, neurons are grouped into three layers interconnected as an input layer, one or more added hidden layers and the last is an output layer. It is in the first processing step of the hybrid structure, corresponding to model $Y$ and $X$ variables respectively [10]. The relationship between the input and the output parameters can be functionally presented as $\mathrm{X}=f(\mathrm{Y})$. In the present research, the input parameter is $Y_{f}=[f]^{T}$ ( $f$ is 100 -frequency samples) and the predicted output is $X_{M L P}=\left[L_{1}, L_{2}, L_{3}, W_{1}, W_{4}\right]^{T}$.The input and the output response can be functionally presented as:

$$
\begin{gathered}
X_{M L P}=f_{M L P}\left(Y_{f}\right) \\
Y_{M L P}=f_{E M}\left(X_{M L P}\right)
\end{gathered}
$$

\subsection{Source difference modeling method (SD)}

Differently from the previous network architecture, SD is the method at the second training step of the first phase which is considered a knowledge-based neural network (KBNN) [10] The concept of SD is integrating collected two of training datasets together to be the target for the new model. These data sets are 3D-EM simulation outputs of $X_{f}=\left[L_{1}, L_{2}, L_{3}, W_{1}, W_{4}\right]^{T}$ and $\mathrm{X}_{\mathrm{MLP}}=\left[\mathrm{L}_{1}, \mathrm{~L}_{2}, \mathrm{~L}_{3}, \mathrm{~W}_{1}, \mathrm{~W}_{4}\right]^{\mathrm{T}}$ which represents the fine information and the information of the output of MLP $\left(X_{M L P}\right)$ respectively. Therefore, the input parameters for MLP in first training step and SD in second training step are only the frequency samples $Y_{f}=[f]^{T} . X_{S D}$ represents predicted output, while the target is $\Delta X_{S D}=X_{f}-X_{M L P}$ as shown in Figure 5 .

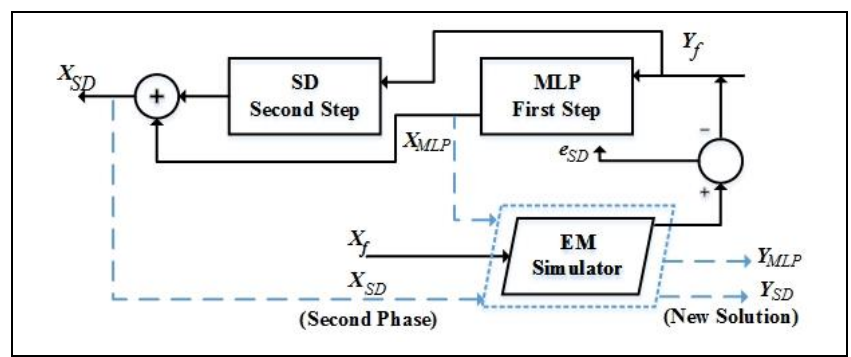

Figure 5. Hybrid structure including SD modeling in the second training step.
The relationship between the input and the output of the design case of 3D-EM simulation and ANNs are functionally presented as:

$$
\begin{gathered}
Y_{S D}=f_{E M}\left(X_{S D}\right) \\
Y_{M L P}=f_{E M}\left(X_{M L P}\right) \\
X_{S D}=f_{A N N S}\left(Y_{f}\right)+X_{M L P}
\end{gathered}
$$

where $Y_{S D}$ is the optimum frequency $\left(f_{\text {opt }}\right)$ that is obtained by designing of the predicted model of $X_{S D} . e_{S D}$ is the error measure expresses the absolute difference between $f_{o p t}$ and $Y_{f}$ and it can be presented as:

$$
e_{S D}=\left|f_{o p t}-Y_{f}\right|
$$

\subsection{Prior knowledge input modeling method (PKI)}

In this method [10], the output of $\operatorname{MLP}\left(X_{M L P} \mathrm{X}_{C}\right)$ is considered the input of PKI (second training step), in addition to the original input of $Y_{f}$ which is an extra knowledge $Y_{\mathrm{f}}$. The target output is the fine output $\left(X_{f} X_{f}\right)$. Therefore, the mapping of input/output is between the output of $\operatorname{MLP}\left(X_{M L P} X_{c}\right)$ and $\left(Y_{f} Y_{f}\right)$ in addition to the target of PKI. The special feature is enhanced by including input parameters of the fine model $\left(Y_{f}\right)$ as additional inputs to the PKI in the second training step. Therefore, the PKI input parameters can be presented as $Y_{f-P K I}=\left[Y_{f}, X_{M L P}\right]^{T}$ which is shown in Figure 6.

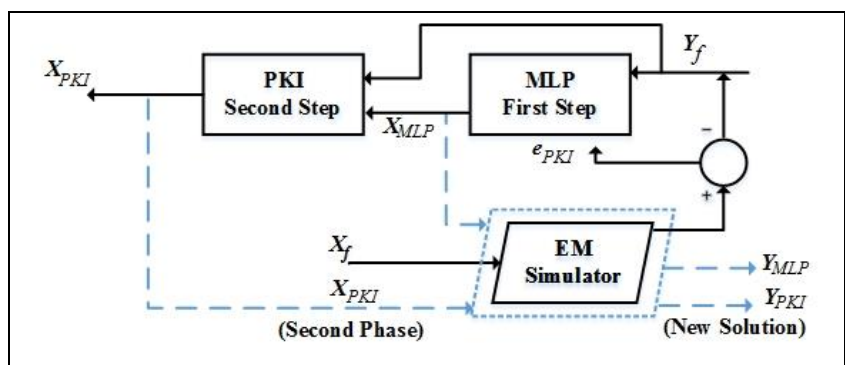

Figure 6. Hybrid structure including PKI modeling in the second training step.

Like the previous modeling case, the relationship between the input and the output of the design case of 3D-EM simulation and ANNs modeling are, respectively, presented as:

$$
\begin{gathered}
Y_{P K I}=f_{E M}\left(X_{P K I}\right) \\
Y_{M L P}=f_{E M}\left(X_{M L P}\right) \\
X_{P K I}=f_{A N N S}\left(Y_{f}, X_{M L P}\right)
\end{gathered}
$$

\subsection{Prior knowledge input with difference modeling method (PKID)}

PKID totalizes the advantages of PKI and SD knowledge-based modeling methods as introduced in [9][13]. The quality of the mapping here is enhanced by entering the knowledge obtained from MLP $\left(X_{M L P}\right)$ with the knowledge of $\left(Y_{f}\right)$ to be PKID's inputs in the second training step. Therefore, the input parameter is $Y_{f-P K I D}=\left[Y_{f}, X_{M L P}\right]^{T}$, when the target is $\Delta X_{P K I D}=X_{f}-X_{M L P}$ as shown in Figure 7. 


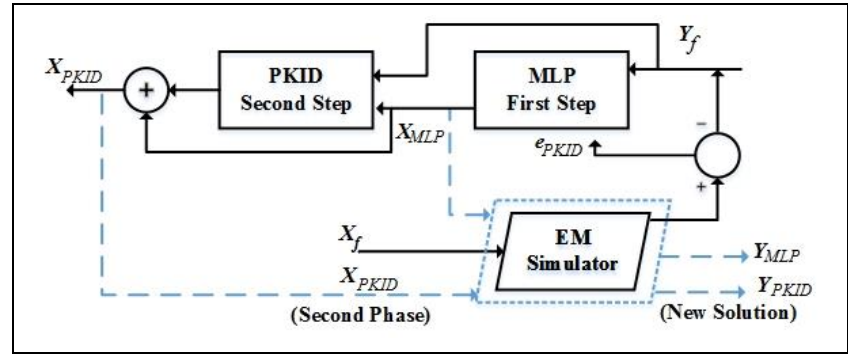

Figure 7. Hybrid structure including PKID modeling in the second training step.

For 3D-EM simulation and ANNs modeling, (14), (15) and (16) present functionally the relationship between the input and the output parameters in the first training and second modeling phases as shown in Figure 7.

$$
\begin{gathered}
Y_{P K I D}=f_{E M}\left(X_{P K I D}\right) \\
Y_{M L P}=f_{E M}\left(X_{M L P}\right) \\
X_{P K I D}=f_{A N N S}\left(Y_{f}, X_{M L P}\right)+X_{M L P}
\end{gathered}
$$

\section{Preprocessing and training of neural networks}

Neural model development starts by generating and collecting data for training and testing process. Therefore, there are two data sets simulated: "Training data set" and "interpolation/extrapolation testing data sets". Two hidden layers are used for all networks. However, the number of hidden neurons is $(60-40)$ used for MLP and KBNNs. A feedforward network computes the outputs of the 100-sample inputs as compositions of $(60-40)$ hidden neurons. Number of hidden layers and their neurons based on the nature, nonlinearity and complexity of the function/problem which are mapped by the network structure. Highly nonlinear problems need more hidden neurons and regular problems need fewer hidden neurons. The output neurons are responsible for presenting results (models), which result from the processing performed by the neurons in the previous hidden layers. ANNs have been developed by applying the Levenberg-Marquardt algorithm (LMA) which is used for adapting weights, with tangent-sigmoid transfer functions (TFs) that is used for mapping the input layer to the output layer within certain bounds as in the case in the biological neuron. Both are inside neurons of the hidden layer. Purely linear function is inside the output layer for calculating a layer's output from its net input. The training parameters of the ANNs are optimized as shown in Table 2.

Table 2. ANN training parameters.

\begin{tabular}{ccc}
\hline Parameters & MLP & KBNN \\
\hline Learning rate $(\boldsymbol{\eta})$ & 0.1 & 0.05 \\
Performance goal & 0.000001 & 0.000001 \\
Momentum coefficient $(\mu)$ & $\begin{array}{c}0.2 \text { (ON-ON state) } \\
0.2 \text { (OFF-OFF state) } \\
0.1 \text { (ON-OFF state) }\end{array}$ & 0.2 \\
Regularization coefficient & 0.2 & 0.2 \\
\hline
\end{tabular}

Both MLP and KBNNs structures are trained for producing new models by using MATLAB-Neural Networks.

\section{Results and discussion}

The first phase of the hyper structure is for training ANN models. For stable results, the training process has been achieved by 50 -iterations. The geometrical parameters of the RNSMA are calculated on the testing data sets. The first phase of the hybrid structure is trained with 3,125-samples to achieve the accuracy that is like that have been obtained by 3D-EM simulation. The accuracy of the models is presented by the optimum value of the S-parameters (frequency and the return loss) of which are the results of simulating geometrical parameters that obtained by the hybrid structure for interpolation and extrapolation test data sets. Numerical results that are shown in the following tables represent the value of the antenna parameters obtained by running of ANNs (MLP, SD, PKI and PKID) at different ON/OFF switching states.

In the next sub-paragraphs, each switching sate contains numerical tables for antenna parameters, new geometries (models) and S-parameters for RNSMA. In addition to the result of measuring the normalized mean absolute relative error (NMARE) as shown in Table 10. For a RL of the fine model as a target and a prediction $R L$ of ANNs, the NMARE is

$$
N M A R E=\frac{\left|R L_{\text {Target }}-R L_{A N N S}\right|}{\left|R L_{A N N S}\right|}
$$

In order to get an optimal model, model simulations have been completed under the same conditions of the design mentioned in section 2. Geometric transformations are shown on the radiation conductors of models depending on switching states, while no change on the substrate material and the feeding system.

\subsection{ON-ON switching state}

In this state, two of testing data sets are internally chosen from training data which is called interpolation and the third is externally chosen from training data which is called extrapolation. Therefore, the results shown in Table 3, Table 4 and Table 5 are designed by 3D-EM simulator in the second phase to produce new models illustrated in new forms of.

Table 3. Results obtained by hybrid structure with fine model in ON-ON state, $f_{\text {opt }}=2.54 \mathrm{GHz}$.

\begin{tabular}{cccccc}
\hline Parameters & $Y_{f}$ (Fine) & $X_{M L P}$ & $X_{S D}$ & $X_{P K I}$ & $X_{P K I D}$ \\
\hline$L_{1}(\mathrm{~cm})$ & - & 0.6407 & 0.6056 & 0.6325 & 0.6419 \\
$L_{2}(\mathrm{~cm})$ & - & 0.7397 & 0.7102 & 0.7189 & 0.7082 \\
$L_{3}(\mathrm{~cm})$ & - & 1.6240 & 1.6442 & 1.6551 & 1.656 \\
$W_{1}(\mathrm{~cm})$ & - & 0.4360 & 0.4868 & 0.5092 & 0.4543 \\
$W_{4}(\mathrm{~cm})$ & - & 0.8052 & 0.7742 & 0.7734 & 0.7777 \\
$f_{\text {opt }}(\mathrm{GHz})$ & 2.54 & 2.63 & 2.63 & 2.54 & 2.63 \\
$R L(\mathrm{~dB})$ & -34.67 & -15.25 & -19.45 & -25.61 & -17.06 \\
\hline
\end{tabular}

Table 4. Results obtained by hybrid structure with fine model in ON-ON state, $f_{\text {opt }}=4.45 \mathrm{GHz}$.

\begin{tabular}{cccccc}
\hline Parameters & $Y_{f}$ (Fine) & $X_{M L P}$ & $X_{S D}$ & $X_{P K I}$ & $X_{P K I D}$ \\
\hline$L_{1}(\mathrm{~cm})$ & - & 1.7065 & 1.6985 & 1.6454 & 1.6788 \\
$L_{2}(\mathrm{~cm})$ & - & 1.0210 & 1.0194 & 1.0294 & 1.0196 \\
$L_{3}(\mathrm{~cm})$ & - & 1.2751 & 1.3058 & 1.3172 & 1.6560 \\
$W_{1}(\mathrm{~cm})$ & - & 0.9979 & 0.4868 & 1.0070 & 1.3013 \\
$W_{4}(\mathrm{~cm})$ & - & 0.9388 & 0.9263 & 0.9349 & 0.9419 \\
$f_{\text {opt }}(\mathrm{GHz})$ & 4.45 & 4.54 & 4.45 & 4.45 & 4.45 \\
$R L(\mathrm{~dB})$ & -26.47 & -23.15 & -23.98 & -25.82 & -24.03 \\
\hline
\end{tabular}


Table 5. Numerical results obtained hybrid structure with fine model in ON-ON state, $f_{\text {opt }}=5.36 \mathrm{GHz}$.

\begin{tabular}{cccccc}
\hline Parameters & $Y_{f}$ (Fine) & $X_{M L P}$ & $X_{S D}$ & $X_{P K I}$ & $X_{P K I D}$ \\
\hline$L_{1}(\mathrm{~cm})$ & - & 1.7532 & 1.8359 & 1.8658 & 1.8322 \\
$L_{2}(\mathrm{~cm})$ & - & 0.7124 & 0.7024 & 0.7260 & 0.7059 \\
$L_{3}(\mathrm{~cm})$ & - & 0.8760 & 0.8523 & 0.8309 & 0.8196 \\
$W_{1}(\mathrm{~cm})$ & - & 0.9512 & 0.9732 & 0.9861 & 0.9750 \\
$W_{4}(\mathrm{~cm})$ & - & 0.9512 & 0.8010 & 0.7787 & 0.7611 \\
$f_{\text {opt }}(\mathrm{GHz})$ & 5.36 & 5.27 & 5.36 & 5.36 & 5.36 \\
$R L(\mathrm{~dB})$ & -50.23 & -35.76 & -34.24 & -31.41 & -62.77 \\
\hline
\end{tabular}

$X_{M L P}$ with their S-parameters as shown in the following Figures (Figure 8, Figure 9, Figure 10, Figure 11, Figure 12 and Figure 13).

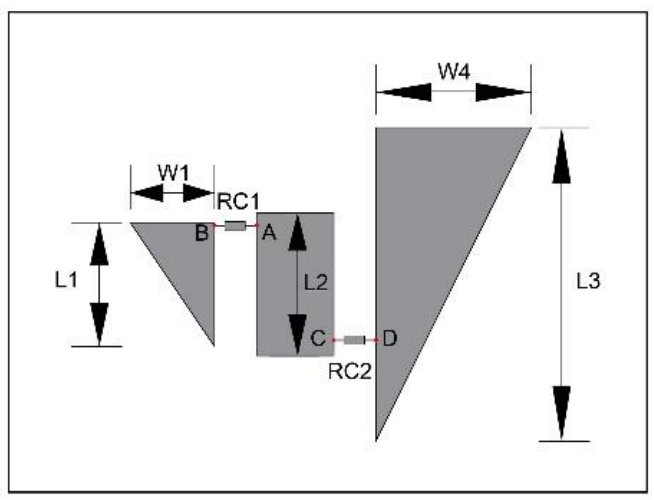

Figure 8. Production of a new model of RNSMA by using parameters of $X_{M L P}, f_{\text {opt }}=2.54 \mathrm{GHz}$.

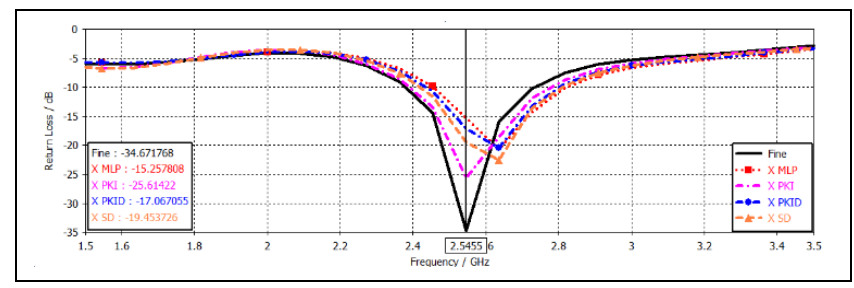

Figure 9. S-parameters produced by simulating ANNs results compared with fine, $f_{\text {opt }}=2.54 \mathrm{GHz}$.

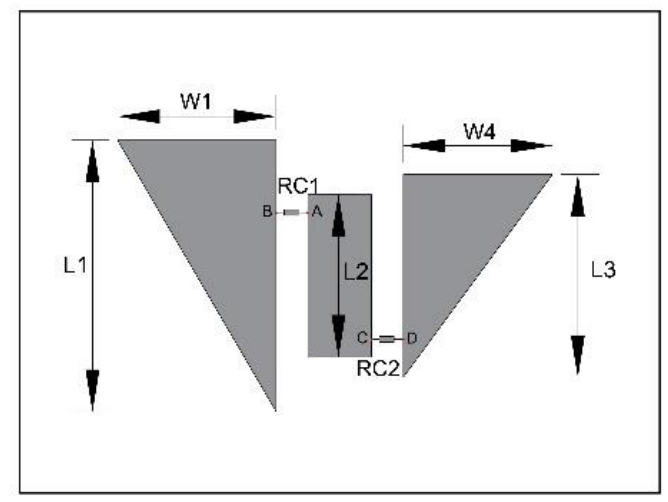

Figure 10. Production of a new model of RNSMA by using parameters of $X_{M L P}, f_{\text {opt }}=4.45 \mathrm{GHz}$.

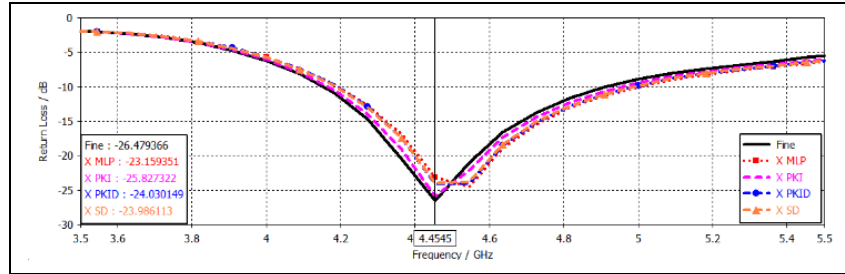

Figure 11. S-parameters produced by simulating ANNs results compared with fine, $f_{\text {opt }}=4.45 \mathrm{GHz}$.

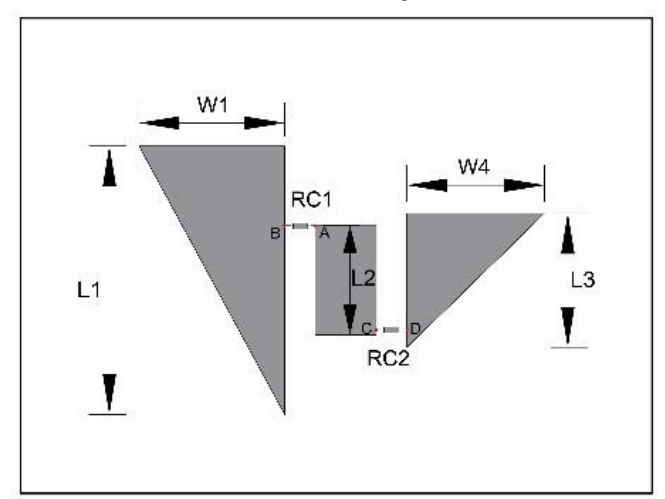

Figure 12. Production of a new model of RNSMA by using parameters of $X_{M L P}, f_{o p t}=5.36 \mathrm{GHz}$.

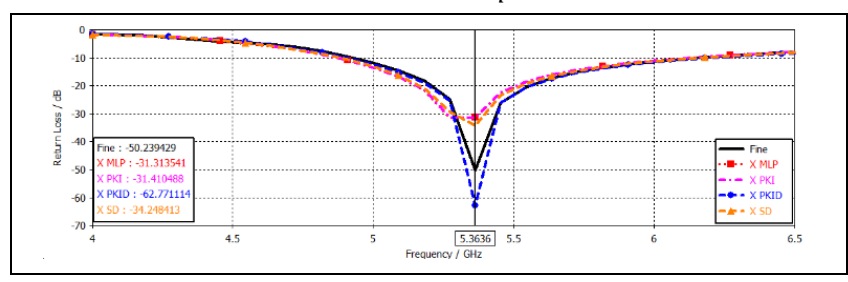

Figure 13. S-parameters produced by simulating ANNs results compared with fine, $f_{o p t}=5.36 \mathrm{GHz}$.

In this case, all conductive parts of the antenna are connected by resistor circuits ( $\mathrm{ON}-\mathrm{ON}$ state) and the current is distributed on each conducting part which has different sizes, and consequently there was a change in results which means getting new models. Note that values of antenna parameters shown in Figure 8 and similar following figures are only the values of MLP models while there is a difference in values of antenna parameters of KBNN models as shown in Table 3 and similar following tables.

\section{$5.2 \quad$ ON-OFF switching state}

Two testing data sets are derived by choosing new adjoining samples next to the middle samples of the training data while keeping minimum and maximum values of parameters as shown in Table 1 [9], a similar process is realized in OFF-OFF state as well. Table 6 and Table 7 summarize the new models of RNSMA which their results are shown in the following Figures (Figure 14, Figure 15, Figure 16 and Figure 17). 
Table 6. Numerical results obtained by hybrid structure with fine model in ON-OFF state, $f_{\text {opt }}=3 \mathrm{GHz}$.

\begin{tabular}{cccccc}
\hline Parameters & $Y_{f}$ (Fine) & $X_{M L P}$ & $X_{S D}$ & $X_{P K I}$ & $X_{P K I D}$ \\
\hline$L_{1}(\mathrm{~cm})$ & - & 1.6791 & 1.6718 & 1.6702 & 1.6777 \\
$L_{2}(\mathrm{~cm})$ & - & 1.4826 & 1.5153 & 1.5412 & 1.5424 \\
$L_{3}(\mathrm{~cm})$ & - & 0.9492 & 0.9505 & 0.9349 & 0.9463 \\
$W_{1}(\mathrm{~cm})$ & - & 0.9614 & 0.9598 & 0.9581 & 0.9423 \\
$W_{4}(\mathrm{~cm})$ & - & 1.5410 & 1.5568 & 1.5216 & 1.5607 \\
$f_{\text {opt }}(\mathrm{GHz})$ & 3 & 3 & 3 & 3 & 3 \\
$R L(\mathrm{~dB})$ & -18.11 & -18.06 & -18.05 & -17.56 & -17.90 \\
\hline
\end{tabular}

Table 7. Numerical results obtained by the hybrid structure with fine model in ON-OFF state, $f_{o p t}=4 \mathrm{GHz}$.

\begin{tabular}{|c|c|c|c|c|c|}
\hline Parameters & $Y_{f}$ (Fine) & $X_{M L P}$ & $X_{S D}$ & $X_{P K I}$ & $X_{P K I D}$ \\
\hline$L_{1}(\mathrm{~cm})$ & - & 1.0390 & 1.0301 & 1.0304 & 1.0336 \\
\hline$L_{2}(\mathrm{~cm})$ & - & 1.3618 & 1.3832 & 1.4029 & 1.4077 \\
\hline$L_{3}(\mathrm{~cm})$ & . & 0.8498 & 0.8315 & 0.7965 & 0.8107 \\
\hline$W_{1}(\mathrm{~cm})$ & - & 0.8460 & 0.8231 & 0.8244 & 0.8200 \\
\hline$W_{4}(\mathrm{~cm})$ & - & 1.3772 & 1.4072 & 1.4009 & 1.4037 \\
\hline$f_{\text {opt }}(\mathrm{GHz})$ & 4 & 4.10 & 4.06 & 4 & 4 \\
\hline$R L(\mathrm{~dB})$ & -17.49 & -17.42 & -17.34 & -17.57 & -17.57 \\
\hline
\end{tabular}

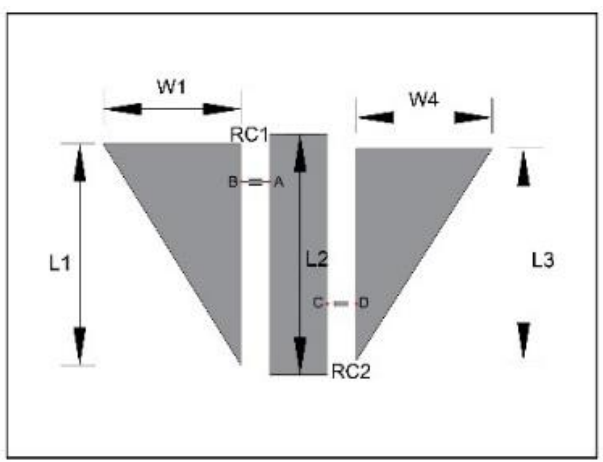

Figure 14. Production of a new model of RNSMA by using parameters of $X_{M L P}, f_{o p t}=3 \mathrm{GHz}$.

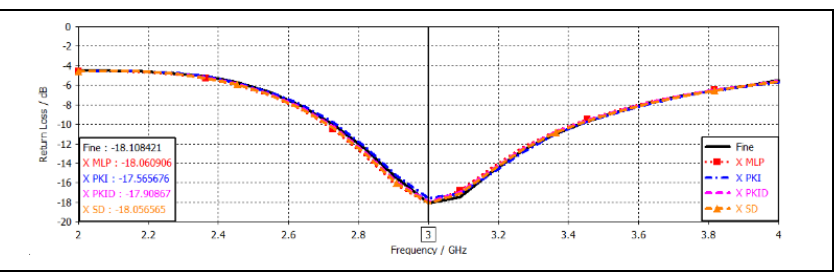

Figure 15. S-parameters produced by simulating ANNs results compared with fine, $f_{\text {opt }}=3 \mathrm{GHz}$.

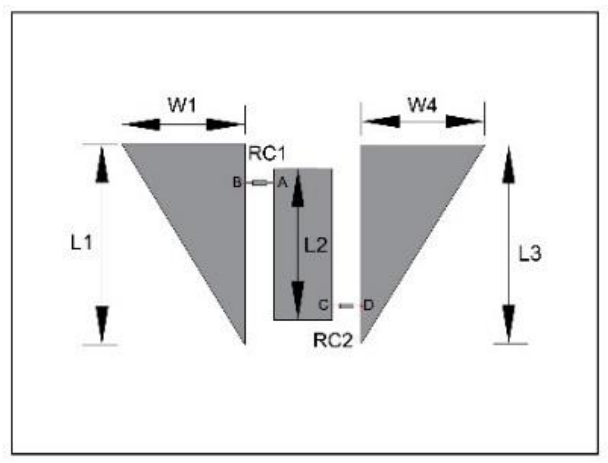

Figure 16. Production of a new model of RNSMA by using parameters of $X_{M L P}, f_{o p t}=4 \mathrm{GHz}$.

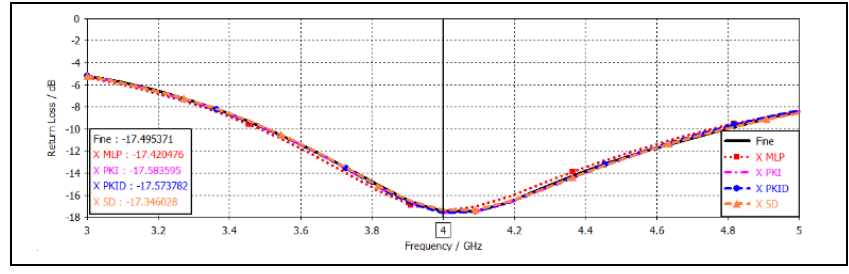

Figure 17. S-parameters produced by simulating ANNs results compared with fine, $f_{\text {opt }}=4 \mathrm{GHz}$.

\subsection{OFF-OFF switching state}

Two Interpolation testing data sets falling within the range of the existing training data are chosen. New models of RNSMA are also obtained as shown in the last following tables (Table 8 and Table 9) and figures (Figure 18, Figure 19, Figure 20 and Figure 21). These results show that the model of OFF-OFF state has less non-linearity than the previous states.

Table 8. Numerical results obtained by hybrid structure with fine model in OFF-OFF state, $f_{\text {opt }}=2 \mathrm{GHz}$.

\begin{tabular}{cccccc}
\hline Parameters & $Y_{f}$ (Fine) & $X_{M L P}$ & $X_{S D}$ & $X_{P K I}$ & $X_{P K I D}$ \\
\hline$L_{1}(\mathrm{~cm})$ & - & 1.3051 & 1.3150 & 1.3018 & 1.3186 \\
$L_{2}(\mathrm{~cm})$ & - & 1.1097 & 1.0580 & 1.0329 & 1.0309 \\
$L_{3}(\mathrm{~cm})$ & - & 0.8420 & 0.8573 & 0.8739 & 0.8801 \\
$W_{1}(\mathrm{~cm})$ & - & 0.8763 & 0.9191 & 0.9317 & 0.9505 \\
$W_{4}(\mathrm{~cm})$ & - & 1.0712 & 1.0391 & 0.9870 & 0.9840 \\
$f_{o p t}(\mathrm{GHz})$ & 2 & 2.07 & 2.02 & 2 & 2 \\
$R L(\mathrm{~dB})$ & -17.77 & -18.11 & -17.99 & -18.09 & -17.88 \\
\hline
\end{tabular}

Figure 18. Production of a new model of RNSMA by using parameters of $X_{M L P}, f_{o p t}=2 \mathrm{GHz}$.

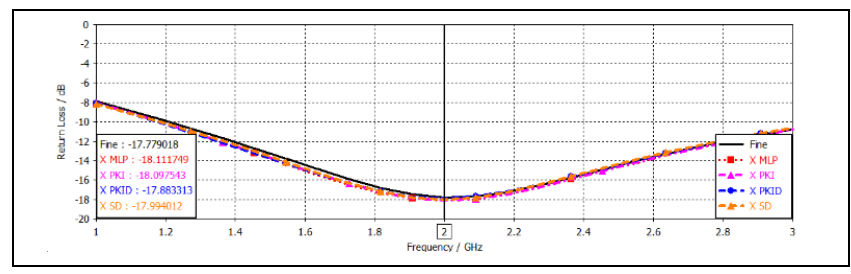

Figure 19. S-parameters produced by simulating ANNs results compared with fine, $f_{\text {opt }}=2 \mathrm{GHz}$.

Table 9. Numerical results obtained by hybrid structure with fine model in OFF-OFF state, $f_{\text {opt }}=1.72 \mathrm{GHz}$.

\begin{tabular}{cccccc}
\hline Parameters & $Y_{f}$ (Fine) & $X_{M L P}$ & $X_{S D}$ & $X_{P K I}$ & $X_{P K I D}$ \\
\hline$L_{1}(\mathrm{~cm})$ & - & 1.6555 & 1.6647 & 1.6711 & 1.6667 \\
$L_{2}(\mathrm{~cm})$ & - & 1.4918 & 1.5210 & 1.5795 & 1.5693 \\
$L_{3}(\mathrm{~cm})$ & - & 0.9888 & 1.0002 & 1.0037 & 1.0213 \\
$W_{1}(\mathrm{~cm})$ & - & 0.9412 & 0.9321 & 0.9028 & 0.9133 \\
$W_{4}(\mathrm{~cm})$ & - & 1.5695 & 1.5614 & 1.5202 & 1.5311 \\
$f_{\text {opt }}(\mathrm{GHz})$ & 1.72 & 1.71 & 1.72 & 1.72 & 1.72 \\
$R L(\mathrm{~dB})$ & -14.94 & -15.16 & -15.05 & -14.92 & -15.02 \\
\hline
\end{tabular}




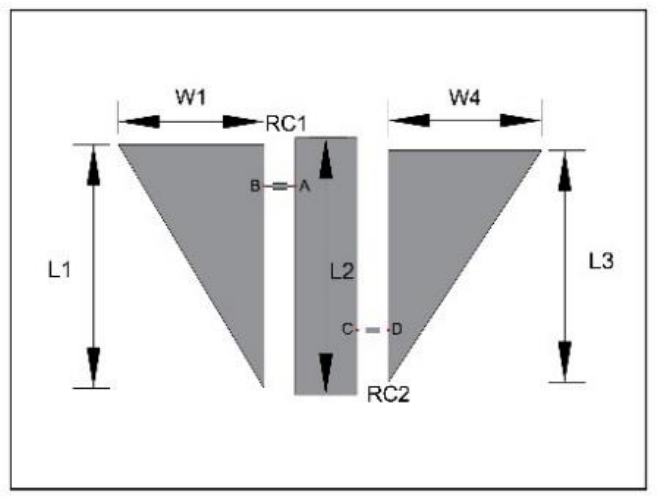

Figure 20. Production of a new model of RNSMA by using parameters of $X_{M L P}, f_{\text {opt }}=1.72 \mathrm{GHz}$.

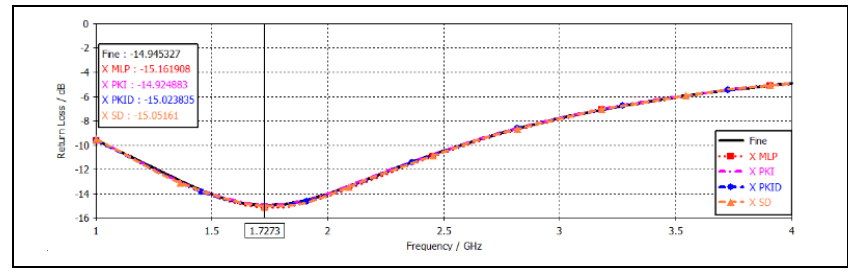

Figure 21. S-parameters produced by simulating ANNs results compared with fine, $f_{\text {opt }}=1.72 \mathrm{GHz}$.

According to the results previously presented, $Y_{f}$ (fine) model (before training ANNs) and predicted model from hybrid structure (after training ANNs) are in a good agreement in the $\mathrm{ON}-\mathrm{ON}$ state. However, they are in an excellent agreement in ON-OFF and OFF-OFF states with a difference of the antenna forms and return losses. Table 10 shows the prediction accuracy and proves the agreement between ANNs and the proposed models.

Table 10. NMARE results of ANNs for RL at all switching states.

\begin{tabular}{cccccc}
\hline Switching state & $\begin{array}{l}f_{\text {opt }} \\
\text { (GHz) }\end{array}$ & MLP & SD & PKI & PKID \\
\hline ON-ON & 2.54 & 0.5601 & 0.4390 & 0.2613 & 0.5079 \\
& 4.45 & 0.1254 & 0.0941 & 0.0246 & 0.0922 \\
ON-OFF & 5.36 & 0.2881 & 0.3183 & 0.3747 & 0.2497 \\
& 3 & 0.0028 & 0.0033 & 0.0304 & 0.0116 \\
OFF-OFF & 2 & 0.0040 & 0.0086 & 0.0046 & 0.0046 \\
& 1.72 & 0.0191 & 0.0124 & 0.0180 & 0.0062 \\
& 0.0147 & 0.0074 & 0.0013 & 0.0054 \\
\hline
\end{tabular}

The complexity and non-linearity are clearly shown when all radiating parts of the antenna are connected by the resistor circuits (ON-ON state) but minimized slowly in ON-OFF and OFF-OFF state. This explains the convergence of numerical values of the parameters shown in the result's tables and curves (S-parameters). This minimum difference in convergence between simulated results is created by the switches during controlling states. But there is a big noticeable difference in antenna shapes between simulated results obtained from training ANNs and fine models. It is also noticed that the value of the optimum frequency $\left(f_{\text {opt }}\right)$ of SD, PKI and PKID models is closer to the fine model $\left(Y_{f}\right)$ than MLP models. As a result, increasing the data in the knowledge-based training step is necessary for getting close model to the fine model. As shown the change of the operating frequency depends on switching states which change the configuration of the antenna.
From the above, ANNs can be used to generate new models (solutions) for communication applications. The results illustrate the benefits of the hybrid structure and support the use of this type of structures for designing of reconfigurable and other types of antennas that operate in the obtained frequency bands. 1-6 GHz band is largely harmonized globally for shortdistance licensed/unlicensed antenna applications. As such, an antenna designer/researcher can develop for marketing the same 1-6 GHz module throughout the world with minimal tuning states or changing the type of control switches.

\section{Conclusion}

This study presents new models of the reconfigurable antenna, where any frequency samples between $1-10 \mathrm{GHz}$ can be the input of the proposed hybrid structure that includes ANN methods to obtain new models. 3D-EM simulation results agree with ANN results but have different configurations. The proposed application is introduced as a single reconfigurable microstrip antenna, operating at a wide range of different frequencies. The studied antenna can be used for several wireless communication applications, ranging from $1 \mathrm{GHz}$ to 6 GHz. The hybrid structure can be further applied to different configurations of microstrip antennas.

\section{References}

[1] Bernhard J. Reconfigurable Antennas, California, USA, Morgan \& Claypool Publishers, 2007.

[2] Li T, Zhai H, Wang X, Liang C. "Frequency-Reconfigurable bow-tie antenna for bluetooth, WiMAX, and WLAN applications". IEEE Antennas and Wireless Propagation Letters, 14, 171-174, 2014.

[3] Zhang B, Wang Y, Wang W, Tian Y. "On the downlink throughput capacity of hybrid wireless networks with MIMO". IEEE Accsess, 5, 26086-26091, 2017.

[4] Christodoulou C, Tawk Y, Lane S, Erwin S. "Reconfigurable antennas for wireless and space applications". Proceedings of the IEEE, 100(7), 2250-2261, 2012.

[5] Song T, Lee Y, Ga D, Choi J. "A polarization reconfigurable microstrip patch antenna using PIN diodes". 2012 IEEE Asia Pacific Microwave Conference Proceedings, Kaohsiung, Taiwan, 4-7 December 2012.

[6] Ismail M, Rahim M, Majid H. "The investigation of PIN diode switch on reconfigurable antenna". 2011 IEEE International $R F \quad \& \quad$ Microwave Conference, Negeri Sembilan, Malaysia, 12-14 December 2011.

[7] Khidre A, Lee K, Elsherbeni A. "Circular polarization reconfigurable wideband e-shaped patch antenna for wireless applications". IEEE Transactions on Antennas and Propagation, 61(2), 960-964, 2013.

[8] Chen R, Row J. "Single-fed microstrip patch antenna with switchable polarization". IEEE Transactions on Antennas and Propagation, 56(4), 922-926, 2008.

[9] Aoad A, Simsek M, Aydin Z. "Design of a reconfigurable 5fingers shaped microstrip patch antenna by artificial neural networks". International Journal of Advanced Research in Computer Science and Software Engineering, 4(10), 61-70, 2014.

[10] Zhang Q, Gupta K. Neural Netwoks for RF and Microwave Design. Boston/London, UK, Artech House, 2000.

[11] Zhang Q, Wang F. "Knowledge-Based neural models for microwave design". IEEE Transaction on Microwave Theory and Techniques, 45(12), 2333-2343 1997. 
[12] Watson P, Gupta K, Mahajan R. "Development of knowledge based artificial neural network models for microwave components". 1998 IEEE MTT-S International Microwave Symposium Digest, Baltimore, MD, USA, 7-12 June 1998.

[13] Simsek M, Zhang Q, Kabir H, Sengor N. "The recent Developments in Knowledge Based Neural Modelling". ELSEVIER Procedia Computer Scince, 1(1), 1321-1330, 2010.
[14] Chen Y, Taian Y, Qiang Z, Xu L. "Optimisation of reflection coefficient of microstrip antennas based on KBNN exploiting model". IET Microwaves, Antennas \& Propagation, 12(4), 602-606, 2018. 